\title{
A simple parameterisation of windbreak effects on wind speed reduction and thermal benefits of sheep
}

Rayment, Mark; He, Yufeng; Jones, Pippa J.

\section{Agricultural and Forest Meteorology}

\section{DOI:}

10.1016/j.agrformet.2017.02.032

Published: 28/05/2017

Peer reviewed version

Cyswllt i'r cyhoeddiad / Link to publication

Dyfyniad o'r fersiwn a gyhoeddwyd / Citation for published version (APA):

Rayment, M., He, Y., \& Jones, P. J. (2017). A simple parameterisation of windbreak effects on wind speed reduction and thermal benefits of sheep. Agricultural and Forest Meteorology, 239, 96-107. https://doi.org/10.1016/j.agrformet.2017.02.032

\footnotetext{
Hawliau Cyffredinol / General rights

Copyright and moral rights for the publications made accessible in the public portal are retained by the authors and/or other copyright owners and it is a condition of accessing publications that users recognise and abide by the legal requirements associated with these rights.

- Users may download and print one copy of any publication from the public portal for the purpose of private study or research.

- You may not further distribute the material or use it for any profit-making activity or commercial gain

- You may freely distribute the URL identifying the publication in the public portal?
}

Take down policy

If you believe that this document breaches copyright please contact us providing details, and we will remove access to the work immediately and investigate your claim. 


\section{A simple parameterisation of windbreak 2 effects on wind speed reduction and 3 resulting thermal benefits to sheep}

4 Yufeng He", Pippa J. Jones, Mark Rayment

5 School of Environment, Natural Resources and Geography, Bangor University, Bangor,

6 Gwynedd, LL57 2UW, UK.

$7 \quad *$ Corresponding author: Yufeng He (afp23e@bangor.ac.uk) 
Modelling windbreak effects

\section{Abstract}

10 It is well known that windbreaks can provide favourable conditions for livestock.

11 Determining the benefit of any given windbreak system first requires that the impact of the

12 windbreak on the wind microclimate is characterised, but in practice, modelling wind flow

13 around obstacles is complex and computationally intensive. We report a simple

14 parameterised model to estimate the wind speed reduction around a windbreak. Analytically,

15 model parameters showed close links to the real-world attributes that characterise windbreaks.

16 The model was validated with field measurements on a farmland in the UK; a Monte Carlo

17 simulation was used to measure model parameter uncertainties. Results showed that the

18 model produced an excellent fit to the relative wind speed (i.e. normalized by ambient wind

19 speed) with root-mean-square error of $4 \% \pm 0.5 \%$. The model was further applied to literature

20 data to characterise the dependence of the relative wind speed on windbreak porosity. A

21 field-scale simulation of a sheep grazing system, including an explicit description of wind-

22 chill effects, was conducted to estimate the net gain associated with including a windbreak in

23 sheep productivity. The maximum productivity gain (27\%) was found at a porosity of 0.5 and

24 a wind speed of $12 \mathrm{~m} / \mathrm{s}$. Wind-chill effects were further simulated for lowland and upland environments, and related to ovine-specific thermal tolerance limits. Results showed a distinct response to reduced wind speeds between sites, indicating different levels of thermal risk to livestock and different, microclimate-specific, windbreak benefits for each location.

28 The simplified models proposed in this study provides a generic framework for an efficient and precise quantification of windbreak effects and optimising the design of windbreak systems.

31 Keywords: windbreaks, wind speed reduction, livestock thermal benefits, wind-chill effects 


\section{Introduction}

Windbreaks or shelterbelts have been used in the agricultural landscape for centuries. In cold and windy environments, where potential negative aspects such as drought and stagnant air are insignificant, they are considered to have a generally positive effect on livestock productivity (Brandle et al., 2004; Grace, 1988). Windbreaks afford direct physical protection from a thermally stressful environment (Cleugh, 1998) as generated by high wind, sun and precipitation. Crucially for livestock production, the immediate microclimatic conditions determine energy balance and extent of energetic flux to the environment.

Energy generated by metabolism over and above requirements for vital processes, is, in agricultural systems ideally apportioned to production (i.e. weight gain), but in cold conditions is utilized in meeting the increased demands of thermoregulation (Bianca, 1976). When exposed to a cold and windy environment, the insulating boundary layer formed by fur, hair or fleece is diminished and convective heat loss from the body of the animal to the surrounding environment is thus increased (McArthur and Monteith, 1980a; Mount and Brown, 1982). The resulting decrease in temperature perceived by the organism as a result of this additional heat loss is commonly known as the wind-chill effect, meaning that under wind conditions, animals experience a colder condition than in still-air, and lower than the ambient temperature. Low-wind microclimates provided by windbreaks reduce heat loss and increase overall productivity (Ames and Insley, 1975; McArthur and Monteith, 1980b) as well as lowering lamb mortality (Pollard, 2006).

As endothermic homeotherms, ovines defend internal homeostasis, with a mean core thermal set-point of $39^{\circ} \mathrm{C}$ (with a typical range of $37.9-39.8^{\circ} \mathrm{C}$ (Bligh et al., 1965)). Within a narrow range of environmental temperature (thermo-comfort zone: TCZ, A-A' on Fig. 1), metabolic heat production is sufficient to balance the still-air energetic flux between animal and microclimate without requiring the initiation of additional thermoregulatory strategies. As the thermal gradient between core body temperature and the environment increases, first behavioural, and then physiological, responses must be initiated to maintain core temperature, incurring an increased energetic cost. Animals experiencing temperatures outside the TCZ, but within thermo-neutral zone (TNZ, B-B'; Fig. 1) cease feeding and seek shelter or shade. Beyond the limits of TNZ, physiological changes to the animal's insulation properties and intensification of metabolic heat production, catabolism of tissue and shivering thermogenesis (cold temperature) or increase in evaporative heat loss through sweating or 
panting (high temperature) occur to meet the energetic cost of thermal stress. Once outside lower or upper critical temperature limits (LCT, UCT), probability of death by hypo- or hyperthermia is a direct product of accumulated time and temperature. The thermal limits for an adult sheep are detailed in Fig. 1.

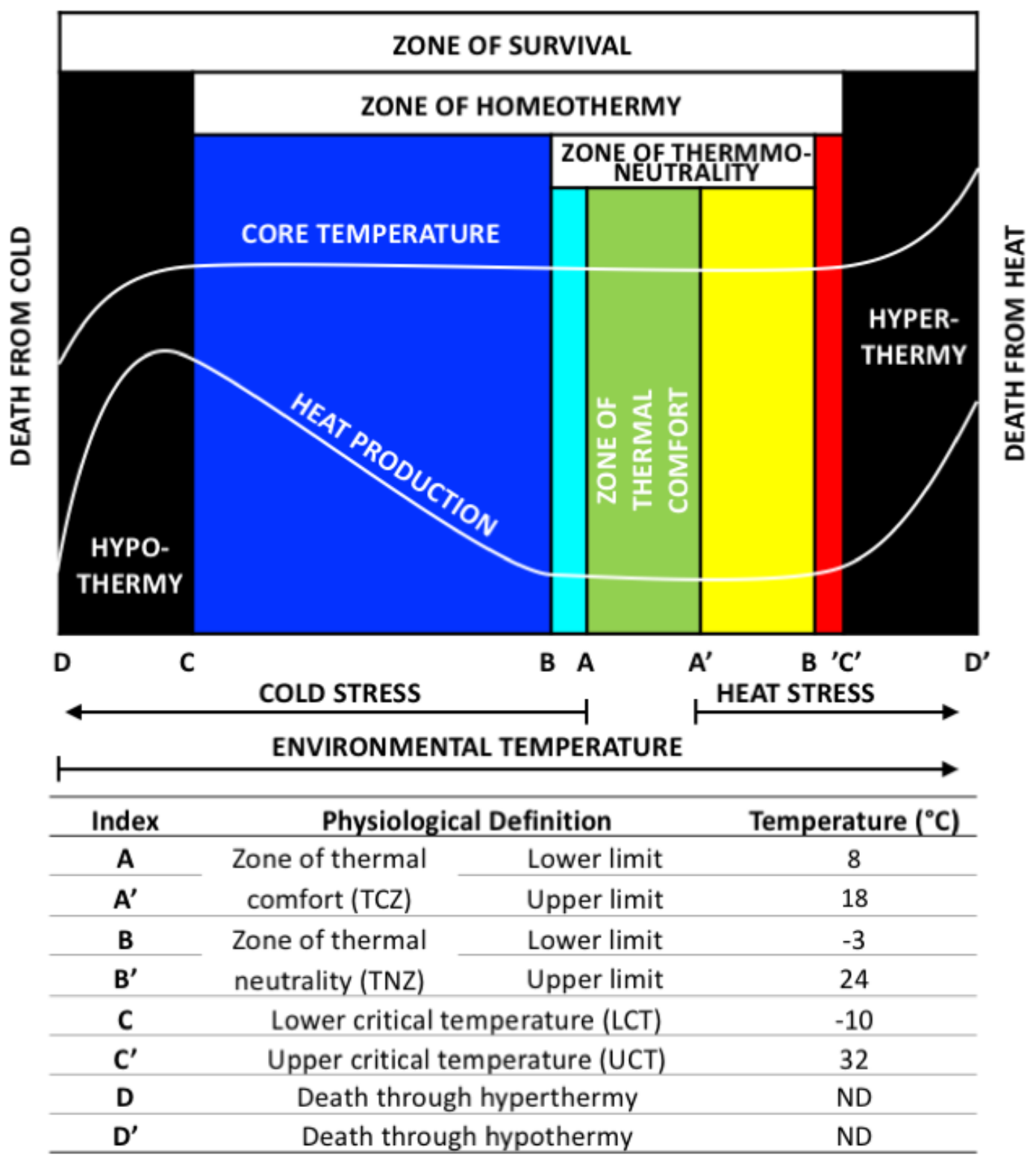

Figure 1 Zones of thermal comfort (TCZ), neutrality (TNZ) and critical thermal limits illustrated graphically with equivalent temperatures for a temperate acclimatised adult ewe on maintenance diet with $50 \mathrm{~mm}$ of fleece shown below. Graph adapted from: (Bianca, 1968); Temperature source: (Bianca, 1971, 1968; Blaxter, 1962; CAgM report, 1989).

72 It is intuitive, therefore, that farm planning should be conducted with consideration of the influence of microclimate on energetic balance and production, and providing outdoor raised

74 livestock with shelter, such as windbreaks. However, the positioning of sheltering 'green 75 infrastructure' such as hedgerows, shelterbelts etc. in the UK is often done either on an 'ad 76 hoc' basis, based on farmer experience, intuition or convenience, or by re-establishing 
historical field boundaries. There is therefore a concern for scientific evidence-based advice in optimising 'weather-wise' farm planning.

Prior to studying the thermal benefits to livestock created by windbreaks, it is fundamental to have a quantitative evaluation of the windbreak impacts on microclimate such as wind field, temperature and humidity. The impacts have been found to be significant in various environmental conditions (McDonald et al., 2007; Nord, 1991; Středa et al., 2011), however, this is generally a highly non-linear process that varies with inter-correlated environmental drivers such as windbreak types, air flow, solar radiation and rainfall. The aerodynamic properties of a windbreak determine its effectiveness in altering leeward microclimate, but due consideration must also be given of the characteristics of the object to be projected (Zhang et al., 1995). The aerodynamic properties of a living windbreak may also be affected by seasonal variation in structure (e.g. deciduousness) (Koh et al., 2014).

In the scientific literature, there have been many attempts to grapple with numerical simulations of the equations that govern windbreak aerodynamics (e.g. Bitog et al., 2012; Speckart and Pardyjak, 2014; Torita and Satou, 2007; Wang and Takle, 1995; Yusaiyin and Tanaka, 2009; Zhou et al., 2007, 2005). In addition to the technical problems of solving these partial differential equations (e.g. how to discretize the equations and choose an appropriate grid size), a fundamental obstacle to using these models in the field is that they are typically derived from wind tunnel experiments that are necessarily simplified and unrealistic given the complexity of a real windbreak (i.e. one made up of flexible and irregularly-shaped trees and leaves). Moreover, the procedure of implementing such simulations is computational intensive and is cumbersome to apply to any real-world scenario. In short, there is a need for a simple parameterized model, based on real-world observations, that can provide not only a computationally-efficient estimation of the wind speed reduction around a real windbreak, but also the follow-up quantification of the effects of that windbreak on livestock productivity. Several previous researchers have tried to build and/or apply a parameterized model to estimating the wind speed reduction around a windbreak. Vigiak et al. (2003) used a function with five parameters (analogous to the sum of two normal distributions) and Stredova et al. (2012) suggested a quadratic polynomial with six parameters, to describe the wind speed reduction against distance and optical porosity. In both of these cases, however, crucial information is missing in terms of how, or whether, these parameters have any physical meaning or any relation to attributes of windbreaks that might be measured in the field. 
110 Critically, only three parameters are required to characterize relative wind speed reduction 111 around a windbreak (Heisler and Dewalle, 1988; Wang and Takle, 1997; Yusaiyin and

112 Tanaka, 2009). These are illustrated in Fig. $2 ; L_{20}, x_{\min }$ and $y_{\min }$, where $L_{20}$ is the distance

113 between which the wind speed reduction is $20 \%$ (i.e. wind speed is $80 \%$ of ambient wind

114 speed), $x_{\min }$ is the distance downwind of the windbreak at which wind speed is at its lowest,

115 and $y_{\min }$ is the minimum wind speed (i.e. the wind speed at $x_{\min }$ ). Consequently, a simple

116 parameterisation of the wind speed around a windbreak is achievable in principle because 1)

117 just three parameters should be sufficient to uniquely determine the trend of wind speed

118 around a windbreak; 2) further downwind of the windbreak, the wind speed asymptotically

119 approaches the ambient wind speed (i.e. zero reduction).

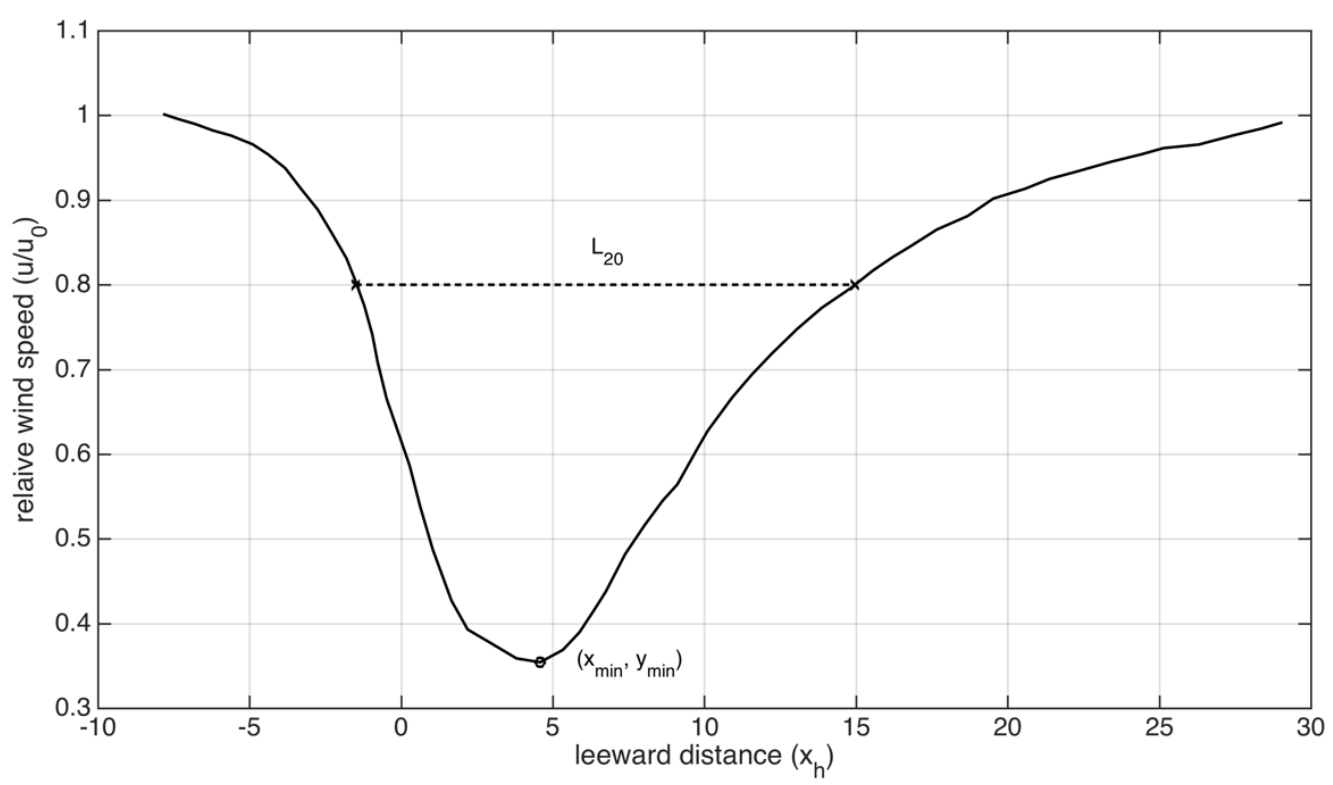

Figure 2 Characteristic trend of wind speed reduction around a windbreak and parameters required to define this.

122 In this study we use a simple parameterized model based on the form of the probability

123 density function of a single logarithmic normal distribution with three parameters, the

124 physical meanings of which can be explicitly expressed in terms of $L_{20}, x_{\min }$ and $y_{\min }$. The

125 estimation error and parameter uncertainty are analysed thoroughly using field measurements

126 and we further extended this model to literature datasets so that the dependence of windbreak

127 effect on windbreak porosity can be estimated and analysed. The wind-chill temperature

128 (WCT) is modelled by using a sigmoid function fitted to a published dataset relating to adult

129 sheep (3-6cm fleece depth). Last but by no means least, we simulate the response of the

130 thermal benefits of wind speed reduction by using historical climate datasets measured at a

131 lowland and an upland site. 


\section{Data and Method}

\subsection{Site description and measurements of wind speed}

134 Field measurements were made at the Bangor University Research farm at Henfaes

$135 \quad\left(53^{\circ} 14^{\prime} 13.2^{\prime \prime} \mathrm{N} 4^{\circ} 00^{\prime} 58.3^{\prime \prime} \mathrm{W}\right)$ in Llanfairfechan, Wales, UK. Five sonic anemometers (four

136 Gill WindSonic 2D and one Campbell CSAT3 3D) were positioned along a transect running

137 perpendicular to a linear tree barrier forming a windbreak. The anemometers were placed at

138 about $1.5 \mathrm{~m}$ above the underlying ground surface, slightly above sheep height. The windbreak

139 was of mixed deciduous species composition in two rows, including sycamore, alder, hazel

140 and oak. Physically, the windbreak had an average height $(\mathrm{H})$ of $10 \mathrm{~m}$ and ran in a southeast -

141 northwest orientation, such that the prevailing wind (from the southwest) meant that the

142 anemometers were situated in the downwind region for most of time. Fig. 3 shows the

143 distance (in $\mathrm{H}$ ) of each anemometer downwind of the windbreak, namely $1 \mathrm{H}, 2.5 \mathrm{H}, 5 \mathrm{H}, 7.5 \mathrm{H}$ 144 and $15 \mathrm{H}$.
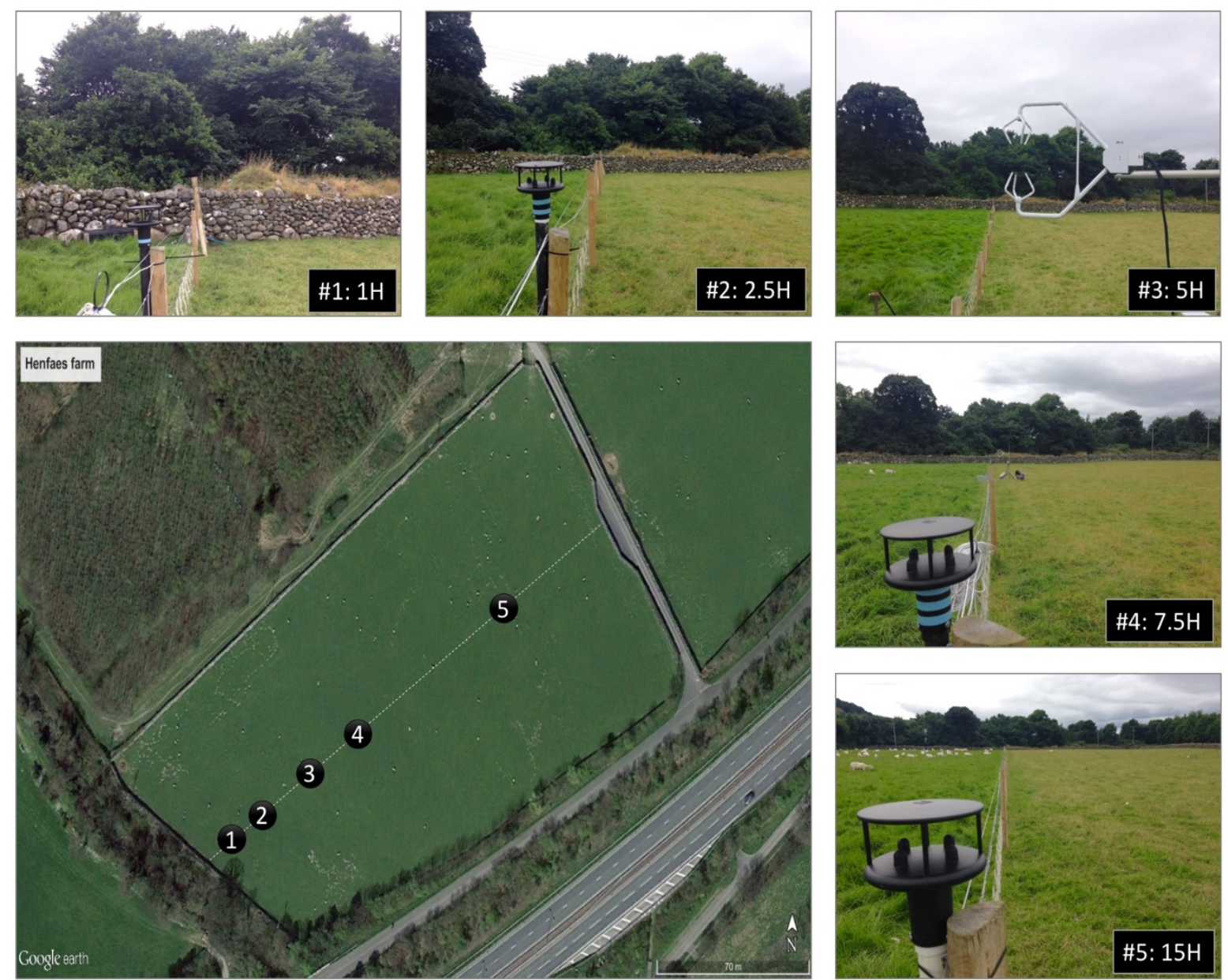

Figure 3 Site map at Henfaes and downwind locations (in barrier height H) of the five sonic anemometers. Photo taken by Y. 
The $2 \mathrm{D}$ and $3 \mathrm{D}$ anemometers sampled at $1 \mathrm{~Hz}$ and $10 \mathrm{~Hz}$ respectively. The $10-$ min averages were then calculated from the valid high frequency samples (i.e. non-nans samples). In total, fourteen days of 10-min averages were collected between 8-22 August 2016. Only data when wind direction was from the southwest sector $\left(180^{\circ}-270^{\circ}\right)$ were included in the simulation. Because southwest is the dominant wind direction for this region, 1353 samples out of 2031 $(67 \%)$ were included.

We assumed that the wind speed measured by the furthest anemometer at $15 \mathrm{H}$ was the reference wind speed and the relative wind speed at each position downwind was normalized by expressing it as a proportion of the wind speed at $15 \mathrm{H}$. Calculating the proportion at each data point exacerbated noise resulting from stochastic events, because the fraction can be significantly impacted by a small change in the numerator and/or denominator, especially when their values are small. For example, an error of 0.1 in the numerator contributes much more to a fraction of $0.5 / 1$ (i.e. $50 \%$ attenuation) than $5 / 10$ (again $50 \%$ attenuation). Therefore, to minimize such errors/uncertainties, the proportion was estimated by taking the slope of the linear regression between wind speed measured by paired anemometers.

\subsection{Model development and error estimation}

Previous attempts to approximate the wind speed reduction around a windbreak have used a single, or the sum of two, normal distributions (Hipsey, 2003; Schwartz et al., 1995; Vigiak et al., 2003). In this study, we modified the density function of a single normal distribution by taking the logarithm of the downwind distance. The relative wind speed $\left(u / u_{0}\right)$ at any distance from a windbreak (i.e. from $-10 h$ windward and up to $40 h$ leeward) can thus be calculated as:

$$
y=\frac{u}{u_{0}}=1-a * e^{-b *\left(\ln \left(x_{h}+10\right)-c\right)^{2}}
$$
where $x_{h}$ is the distance from the barrier normalized by the barrier's height. $u$ is the wind speed at $x_{h}$ and $u_{0}$ is the incoming ambient wind speed. Fig. 2 shows a typical picture of the

173 relative wind speed around a windbreak. The general characteristics of this curve can be expressed by the following, 1) It is asymptotic towards 1 at both ends; 2) It has a single minimum point; 3$)$ The shelter distance $\left(L_{20}\right)$ is defined as the distance between which the wind speed reduction is at least $20 \%$. Coefficients $a, b, c$ in Eq. (1) are closely related to the minimum point and $L_{20}$,

$$
x_{\min }=e^{c}-10
$$


Modelling windbreak effects

$$
y_{\min }=1-a
$$

where $x_{\min }$ represents the downwind location where the minimum wind speed $\left(y_{\min }\right)$ is reached.

This formulation clearly points out the potential physical meanings of the coefficients in Eq. (1). $a$ is related to the maximum wind speed reduction, $b$ is related to the initial deceleration and acceleration of airflow and $c$ is related to the downwind position of $x_{\min }$. They are all dimensionless quantities. In the discussion below, we speculate on how these parameters are related to the physical characteristics of the windbreak.

\subsection{Model error estimation}

In order to determine the robustness of the model, we quantified parameter errors by splitting our dataset randomly into two parts; a training set (70\%) and a validation set (30\%). The training set was used to estimate the parameters in Eq. (1) and the validation set was used to calculate model error that was evaluated by the root mean square error (RMSE). This process was repeated 500 times using a Monte Carlo method to generate independent training and validation sets so that all variation (uncertainty) in the estimations of the coefficients was captured. Note that here we do not require a cross-validation set and test set as used to test an artificial neural network (ANN) procedure. ANNs optimise parameters by iteration and require evaluations on independent cross-validation sets to update coefficient estimates in real time. Our goal, however, is simply to measure the model prediction error through Monte Carlo sampling. In fact, statistically the confidence interval (CI) estimated by this method is more reliable than that associated with an ANN because even poor parameter estimations will be included in the CI estimates.

\subsection{Literature data and windbreak porosity}

Neglecting atmospheric stability, the three parameters (i.e. $x_{\min }, y_{\min }$ and $L_{20}$ ) uniquely define airflow modified by any given windbreak. Despite the fact that a windbreak has a plethora of characteristics (e.g. tree species, leaf shape, density and distribution), optical porosity alone has often been used to describe windbreak aerodynamics and distinguish between windbreak type (e.g. Stredova et al., 2012; Vigiak et al., 2003; Wang and Takle, 1997). In order to build a function of porosity against the parameters in Eq. (1), we applied the model to two published data sets as shown in Fig. 4. For the sake of simplicity, we call the dataset 
extracted from Heisler and Dewalle (1988) dataset 1 and that extracted from Wang and Takle

210 (1997) dataset 2. Dataset 1 was obtained from field observations of five types of windbreak

211 (Fig. 4a) and dataset 2 was the result from numerical simulations of a boundary-layer

212 turbulence model (Fig. 4b). By fitting Eq. (1) to each data set, we estimated the parameters

213 which could then be correlated to reported values of porosity. It should be noted, however,

214 that dataset 1 did not represent porosity numerically, so for the sake of this simulation we

215 assigned values of $0.2,0.36,0.5,0.62$ and 0.73 to the data reported for very dense, dense, 216 medium, loose and very loose respectively.
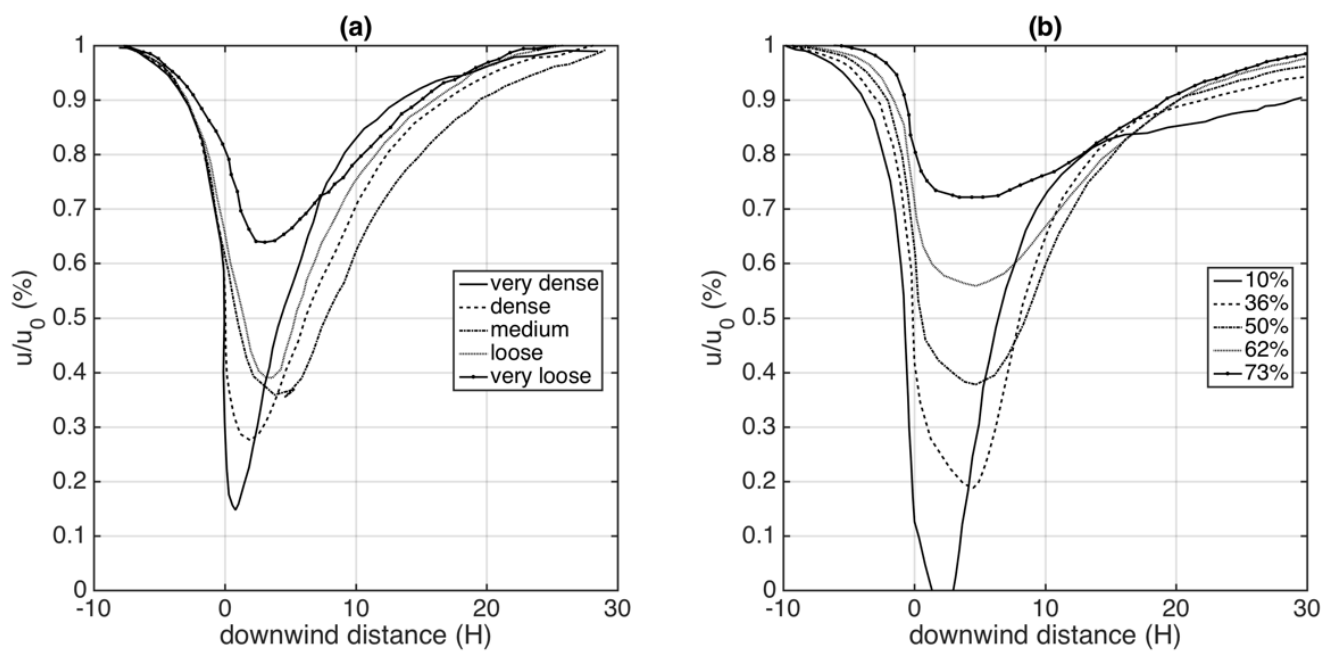

Figure 4 Digitized data extracted from (a) Fig. 2 a in (Heisler and Dewalle, 1988); (b) Fig. 2 in (Wang and Takle, 1997).

\subsection{Wind-chill effects and heat loss from sheep}

220 Barnes (1974) measured the wind-chill temperature (WCT) for sheep with three types of fleece: shorn, medium (3-6 cm) and full $(>6 \mathrm{~cm})$. In the experimental setting, wind speed varied from $0 \mathrm{~m} / \mathrm{s}$ up to $18 \mathrm{~m} / \mathrm{s}$, and temperature varied from $-15^{\circ} \mathrm{C}$ to $20^{\circ} \mathrm{C}$. The equation developed by Osczevski and Bluestein (2005) for wind chill effect in humans, $W C T=$ $35.74+0.6215 * T-35.75 * V^{0.16}+0.4275 * T V^{0.16}$, is unsuitable for the purposes of this study physiologically: the insulation properties and physical proportions of ovines are somewhat different to those of humans. Instead, we used a sigmoid function to fit the data of medium fleece sheep as follows,

$$
W C T=-39+T+\frac{39}{1+e^{0.28 *(V-12.12)}}
$$

where $W C T$ is the wind-chill temperature. $T$ and $V$ signify ambient temperature and ambient wind speed respectively. The goodness of fit was great with $R^{2}=0.98(p<0.01)$ and $\mathrm{RMSE}=2.44$. The value 39 represents sheep core body temperature and the other two values were obtained by curve fitting: 0.28 shows the heat conductance rate and 12.12 is the wind 
233

234

235

236

237

238

239

240

speed above which the wind-chill effect starts to slow down asymptotically. Heat loss (in $\mathrm{W} / \mathrm{m}^{2}$ ) was determined from the $W C T$ (see below).

When ambient temperature is below the lower limits of TNZ, metabolic heat production increases linearly with decreasing ambient temperature (Alexander, 1974) (until outside critical limits and suffering hypothermia), i.e. $\Delta Q=k * \Delta T$. Thus, the reduction of heat loss $\left(P_{Q}\right)$ due to reduced wind-chill effects was calculated as,

$$
P_{Q}=1-\frac{k *(T-W C T)}{k *\left(T-W C T_{0}\right)}=1-\frac{T-W C T}{T-W C T_{0}}
$$

where $T$ is ambient temperature. $W C T$ and $W C T_{0}$ are the wind-chill temperature with and without windbreak effects. $P_{Q}$ is always positive as $W C T \leq T$.

\subsection{Historical climate data}

In order to simulate real-world environments, we used historical datasets from two meteorological stations in North Wales, namely the Llanberis station $\left(53.1180^{\circ} \mathrm{N}, 4.1275^{\circ} \mathrm{W}\right)$ and the Clogwyn station $\left(53.0642^{\circ} \mathrm{N}, 4.0864^{\circ} \mathrm{W}\right)$. The former site is located in a lowland area with an elevation of about $130 \mathrm{~m}$ and the latter in an upland area with an elevation of about $700 \mathrm{~m}$. Therefore, the climatic condition at Clogwyn is generally more extreme (i.e. higher wind speed and wider temperature range) than Llanberis. Hourly wind speed and temperature datasets were directly retrieved from data archives: (http://www.fhc.co.uk/weather/archive/main.asp). Data availability from both sites covered more than 10 years, i.e. from July 1998 to April 2011 for Clogwyn and from July 1999 to September 2015 for Llanberis.

Hourly data were plotted on a graph of wind speed and ambient temperature and a boundary, shown by a polygon, was then drawn to include all data points (excluding obvious data errors). This represents the environmental envelope experienced by livestock at these sites. Please see results, Fig. 9 for graphical details.

\subsection{The metric for the total benefit}

Because our goal is to measure the impact of windbreaks on the heat loss from sheep $\left(P_{Q}\right)$, a single metric representing the total benefit spatially is helpful. We propose the following equation to estimate the total benefit $(B)$, which is simply the average of the integration of $P_{Q}$ over the leeward distance,

$$
B=\frac{1}{x_{1}-x_{0}} \int_{x_{0}}^{x_{1}} P_{Q} d x
$$


Modelling windbreak effects

where $x_{1}$ and $x_{0}$ are the start and end points for the integration.

\section{Results}

\subsection{Model uncertainty of wind speed reduction}

266 The time series of our measurements showed clear and consistent separations among, but

267 good correlation between, the five anemometers (Fig. 5a). As expected, wind speed increased

268 further away from the windbreak. Fig. 5b shows the model fit against the observations

269 located at five downwind positions (i.e. $1 \mathrm{H}, 2.5 \mathrm{H}, 5 \mathrm{H}, 7.5 \mathrm{H}$ and $15 \mathrm{H}$ ). It is clear that the $\log -$ normal function (Eq. 1) captured the trend of wind speed at downwind locations, with only small discrepancies $(\mathrm{RMSE}=0.06)$. The model uncertainty including parameter variation and validation error was further estimated by the 500-repetition Monte Carlo simulation (Fig. 6).

273 The variations in the three parameters of Eq. (1) were almost negligible with standard

274 deviations less than $1 \%$ of the respective mean values for all three parameters (Fig. 6a,

$2756 \mathrm{~b} \& 6 \mathrm{c})$. Similarly, the validation error (RMSE) was between $3.5 \%$ and $4.5 \%$, that is to say, the estimation by the model of the relative wind speed $\left(\mathrm{u} / \mathrm{u}_{0}\right)$ had an average error of $4 \%$. In summary, despite its simple form, the proposed model was capable of capturing most variation in wind speed downwind of the windbreak.

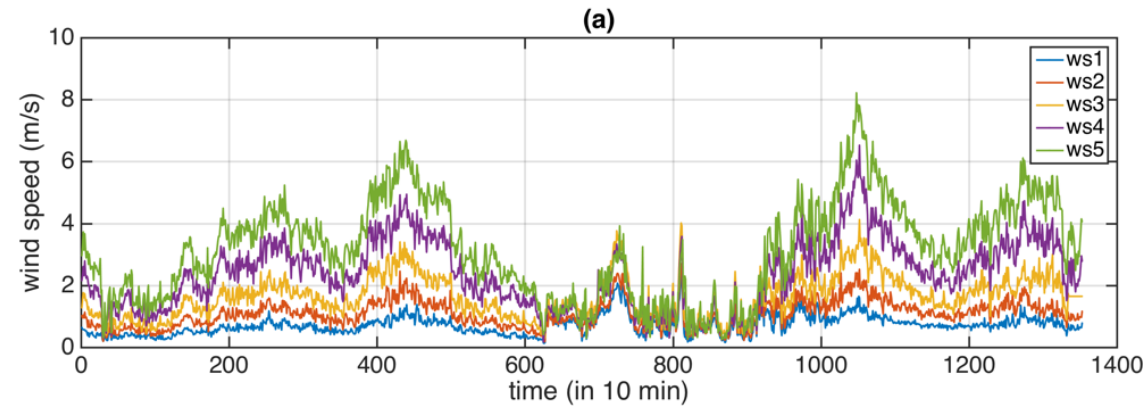

(b)





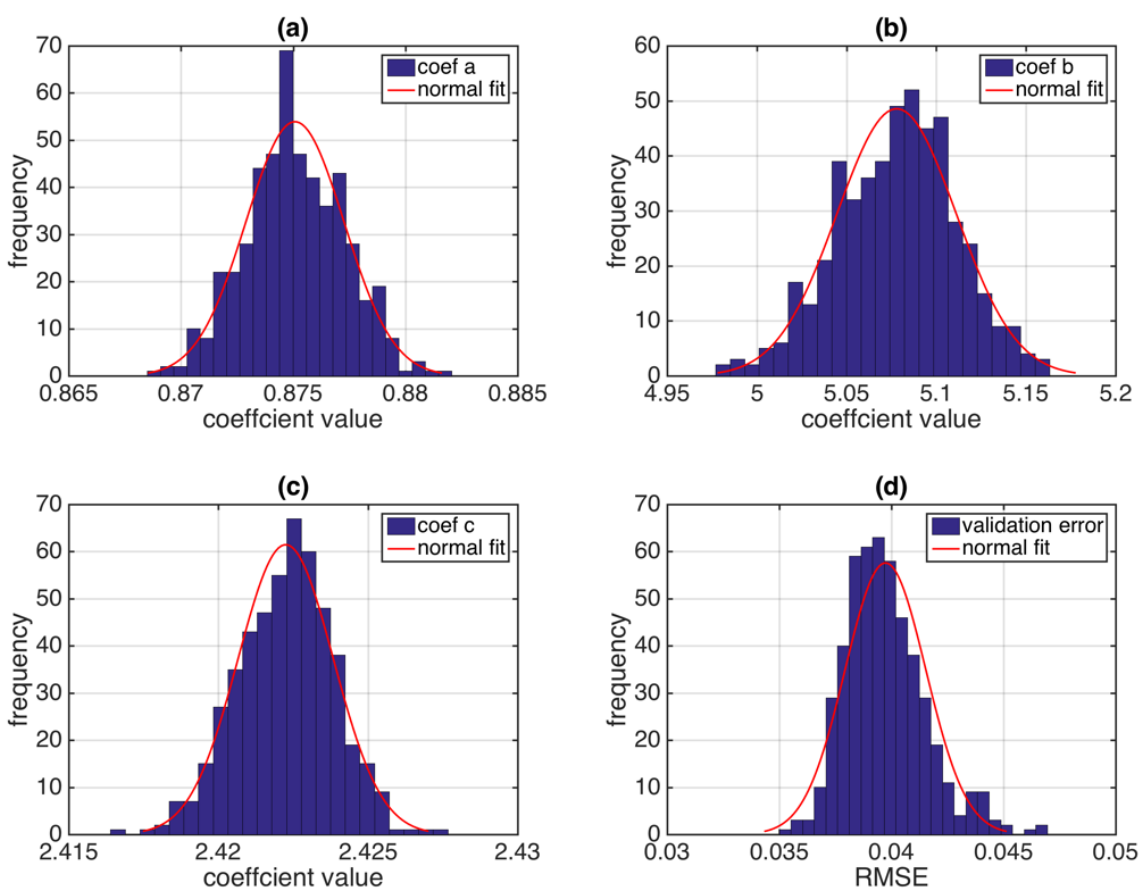

Figure 6 Distributions of the estimation of the coefficients and the model error (RMSE) estimated on the 500 validation datasets generated by the Monte Carlo method.

\subsection{Modelling literature data and porosity dependence}

286 By applying a similar method to the two literature datasets, a sensitivity analysis was conducted to determine how windbreak porosity affected model parameters and RMSE (Table 1). Model performance was consistently good with $\mathrm{R}^{2}$ values over 0.92 for all cases, once again illustrating the robustness of this simple model. RMSE values ranged from 0.01 to 0.08 , meaning that the average estimation error of $\mathrm{u} / \mathrm{u}_{0}$ was between $1 \%$ and $8 \%$. There was a simple dependence of RMSE on porosity: as porosity increased, RMSE decreased, suggesting that the model resulted in smaller uncertainties for sparser windbreaks. This result can also be observed in the dependence of the estimation of coefficients $a$ and $b$ on porosity where the error bars tended to decrease in size as porosity increased. Uncertainties of the coefficient $c$, however, were constantly small for all cases, with a standard deviation of 0.02 .

296 The relationships between porosity and the coefficients themselves was built empirically by

297 fitting the quadratic function $\left(y=m x^{2}+n x+l\right.$, where $\mathrm{x}$ is porosity and $\mathrm{y}$ is a coefficient)

298 as shown in Fig. 7. The fit performance was generally good with $\mathrm{R}^{2}$ over 0.85 for all cases

299 (Fig. 7a \& 7b). Relative wind speed was estimated for windbreaks of different porosity as

300 shown in Fig. 7c \& 7d. As porosity increased, the wind attenuation effects of the windbreak

301 diminished and the point of minimum wind speed tended to move downwind. Although the

302 wind speed curves agreed well between the two literature datasets at a medium porosity of 
Modelling windbreak effects

3030.5 , the two estimations of wind speed differed significantly for other porosities, especially so

304 for the lowest porosity. The windbreak used in our field experiments was clearly very dense

305 (see photos in Fig. 3). Fig. 7e showed that the wind speed curve estimated from our

306 measurements was close to the 0.1 and 0.2 porosity curves from dataset 2 , suggesting that the

307 porosity of the experimental windbreak observed was between 0.1 and 0.2 as defined in

308 dataset 2.

309 Table 1 Model fit to two literature datasets. The codes for dataset 1, XD, D, M, L and XL, represent very dense, dense,

310 medium, loose and very loose respectively. The last column with porosity 1 represents an open area without windbreak,

311 simply used as a boundary condition for parameter a (i.e. $a=0$ when porosity $=1$ ). In the absence of a windbreak parameters

$312 \quad b$ and $c$ are undefined (ND).

\begin{tabular}{c|ccccccc}
\multicolumn{2}{c}{ Porosity } & XD/0.10 & D/0.36 & M/0.5 & L/0.62 & XL/0.73 & O/1 \\
\hline & $\mathrm{RMSE}$ & 0.080 & 0.047 & 0.018 & 0.025 & 0.014 & $\mathrm{ND}$ \\
& $a$ & $0.76 \pm 0.05$ & $0.69 \pm 0.05$ & $0.63 \pm 0.01$ & $0.57 \pm 0.02$ & $0.35 \pm 0.01$ & 0 \\
Dataset 1 & $b$ & $8.19 \pm 1.53$ & $4.85 \pm 0.56$ & $3.89 \pm 0.16$ & $5.00 \pm 0.38$ & $3.95 \pm 0.26$ & $\mathrm{ND}$ \\
& $c$ & $2.48 \pm 0.02$ & $2.57 \pm 0.02$ & $2.65 \pm 0.01$ & $2.59 \pm 0.01$ & $2.64 \pm 0.01$ & $\mathrm{ND}$ \\
& $\mathrm{R}^{2}$ & 0.92 & 0.96 & 0.99 & 0.99 & 0.99 & $\mathrm{ND}$ \\
& $\mathrm{RMSE}$ & 0.084 & 0.046 & 0.030 & 0.022 & 0.018 & $\mathrm{ND}$ \\
& $a$ & $1.00 \pm 0.05$ & $0.82 \pm 0.04$ & $0.63 \pm 0.03$ & $0.45 \pm 0.01$ & $0.29 \pm 0.01$ & 0 \\
Dataset 2 & $b$ & $6.81 \pm 1.04$ & $5.07 \pm 0.54$ & $3.84 \pm 0.35$ & $3.27 \pm 0.28$ & $2.92 \pm 0.28$ & $\mathrm{ND}$ \\
& $c$ & $2.50 \pm 0.02$ & $2.62 \pm 0.02$ & $2.67 \pm 0.02$ & $2.71 \pm 0.02$ & $2.75 \pm 0.02$ & $\mathrm{ND}$ \\
& $\mathrm{R}$ & 0.94 & 0.97 & 0.98 & 0.98 & 0.97 & $\mathrm{ND}$
\end{tabular}



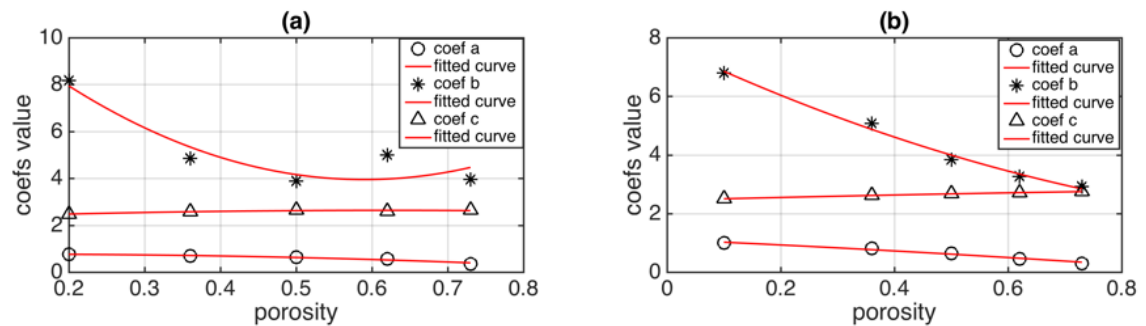

(c)

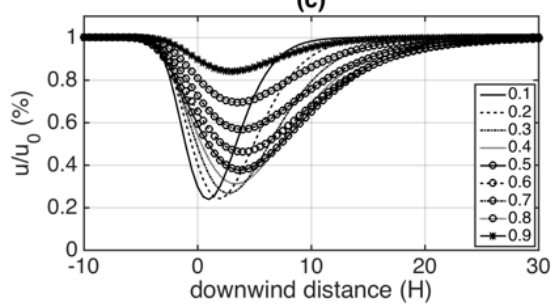

(d)

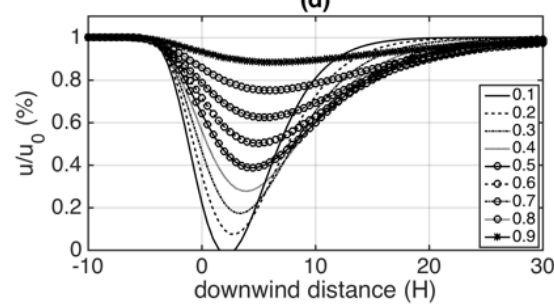

(e)

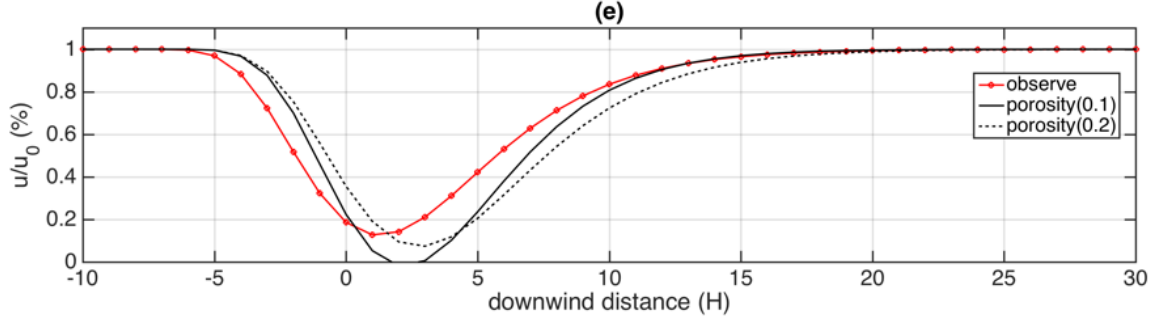

Figure 7 Fitted model parameters and porosity and the curve of relative wind speed for porosity values ranging from 0.1-0.9. $(a, c)$ From dataset 1; (b, d) Dataset 2. (e) Field measurements compared with curves for porosity of 0.1 and 0.2 from dataset 2 .

\subsection{Estimated benefits in reducing heat loss from sheep}

318 Building upon the above results and combining equations (5-7), it was possible to apply the

319 wind speed model to estimate potential climatic benefits due to reduced heat loss from sheep.

320 Fig. 8a shows heat loss reduction under a fixed ambient wind speed of $10 \mathrm{~m} / \mathrm{s}$, an ambient

321 temperature of $5{ }^{\circ} \mathrm{C}$ and a windbreak porosity of 0.2 . Heat loss decreased significantly at the

322 locations near the windbreak because of decreased wind speed and lower wind-chill. In fact,

323 for a given ambient temperature (e.g. $5^{\circ} \mathrm{C}$ here), the reduction in heat loss is highly

324 correlated with the wind speed reduction through Eq. (6).

325 Combining the benefits on heat loss reduction using Eq. (7), we implemented a sensitivity 326 analysis of the total productivity gain against a range of porosities from 0.1-0.9 and ambient 327 wind speed from 1-30 m/s. This relationship is shown as a 2-D contour plot in Fig. 8b. When

328 the air is nearly still (i.e. wind speed close to zero), the total gain is nearly null because of the absence of wind chill. As wind becomes stronger, reduced heat loss gradually increases,

330 adding to the total productivity benefit, suggesting that greater advantages are conferred in

331 windier conditions. The total benefit increased as the ambient wind speed increased for all 332 porosities, but dependence on porosity was not monotonic. The total benefit starts to increase 
333

334

335

336

337

338

339

340

as porosity increases above zero, reaches a peak benefit of $+27 \%$ at a porosity of 0.5 and a wind speed of $12 \mathrm{~m} / \mathrm{s}$, and then starts to fall as porosity approaches 1 . As wind speed increases above $12 \mathrm{~m} / \mathrm{s}$, the total benefit to productivity conferred by the windbreak asymptotically approached a constant because of diminishing wind-chill effects determined by Eq. (5). In physical terms, this can be understood as the gradual erosion of the surface boundary layer as the fleece is penetrated by high winds, leading ultimately to a point where conduction of heat through the endodermis, rather than through the surface boundary layer, limits heat loss.
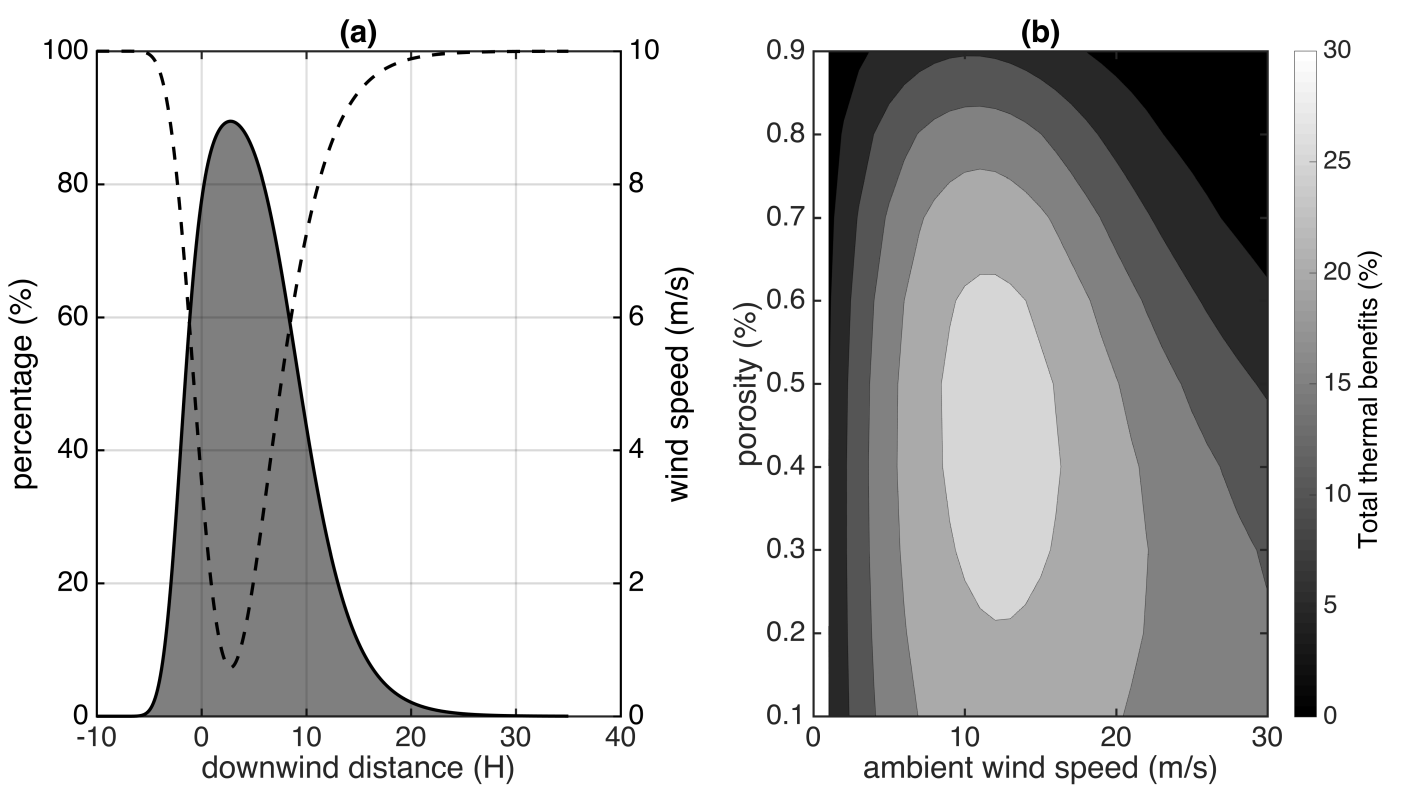

341

343

344

345

346

347

348

349

350

351

352

353

354

355

Figure 8 (a)Effects of windbreak on wind speed (dashed line) and percentage of heat loss (solid line). The shaded area represents the total reduced heat loss from the animal. (b) The integrated total benefit against a range of porosity (0.1-0.9) and ambient wind speed $(1-30 \mathrm{~m} / \mathrm{s})$.

\subsection{Wind-chill effects on a habitable thermal condition}

Based on historical climate data for two sites representative of upland and lowland

environments inhabited by sheep, we related simulated wind-chill to sheep-specific limits of thermal comfort, neutrality and critical tolerance to determine the impact of a chilling wind on the physiology of livestock, and importantly, the influence of reduced wind speed to the physiological response of livestock to the warmer temperature experienced.

Eq. (5) summarises the wind-chill temperature (WCT) as a function of ambient temperature and wind speed. We split the value range of WCT into seven sectors denoted by six physiologically significant temperature points for sheep $\left(-10^{\circ} \mathrm{C},-3^{\circ} \mathrm{C}, 8^{\circ} \mathrm{C}, 18^{\circ} \mathrm{C}, 24^{\circ} \mathrm{C}, 32^{\circ} \mathrm{C}\right)$ in terms of temperature experienced, rather than ambient temperature (see details in Fig. 1) Each sector was assigned to a colour (indicated in Fig. 1) and the relation between critical 
temperature limits and ambient temperature and wind speed are illustrated by filled contour plots (Fig. 9a\&9b), hereafter simply denoted by the term wind-chill thermal tolerance (WTT) plot. The ambient temperature scale from $-40^{\circ} \mathrm{C}$ to $50^{\circ} \mathrm{C}$ and wind speed from 0 to $50 \mathrm{~m} / \mathrm{s}$ represents a generic environment inclusive of most natural microclimates. Any individual location will experience only a sub-area of the WTT plot, corresponding to the environmental conditions experienced over any given time period.

The areas enclosed by the dotted white lines in Fig. 9a and Fig. 9b represented the environmental envelope at Llanberis and Clogwyn stations respectively. As expected, the WTT plot suggested a more physiologically-stressful thermal environment at the upland in Clogwyn, with a large black area indicating the range of WCT temperatures in which a sheep's environmental temperature falls below LCT and the sheep would eventually suffer fatal hypothermia.

Without wind, the boundaries of each monochromatic area on the WTT plot would be mutually parallel (i.e. no dependence on wind speed), but because of the presence of windchill effects, these boundaries bend towards higher temperatures at greater wind speed, creating a larger cold zone and a smaller warm zone. Consequently, the areas representing optimum conditions for livestock health and productivity denoted by the green 'thermocomfort' zone $\left(8-18^{\circ} \mathrm{C}\right.$, green area on Fig. $\left.9 \mathrm{a} \& 9 \mathrm{~b}\right)$ and the wider, sub-optimal but 'thermoneutral' zones (indicated by light blue and yellow areas) become a smaller part of the total micro-climatic environment represented on the graph. As the animal's insulating boundary layer and fleece become compromised, further increases in wind lead to smaller and smaller increases in wind chill, until a point is reached at a wind speed of about $20 \mathrm{~m} / \mathrm{s}$ where the boundaries become parallel and vertical.

The introduction of a windbreak, and the reduction in winds speed and chilling can be visualized on the WTT plot. Here, the probability of experiencing a given thermal environment can be estimated by the proportion of the area it represents (e.g. the proportion of green area at a given wind speed shows the probability of having a thermo-comfortable temperature). Therefore, reducing ambient wind speed by a certain amount (e.g. moving the dashed horizontal lines in Fig. 9a\&9b downwards), reduces the relative area of hypo/hyperthermy (black) and increases the relative areas of thermocomfort and thermoneutrality (green, yellow, light blue). 
We used the historical climate data to constrain our simulation to a real-world scenario (i.e. only the area within the polygon representing the actual climatic envelope was considered in the computation). The four coloured lines in Fig. 9c\&9d represent the changed probability of experiencing thermocomfort (green), thermoneutral (light blue) and thermostress (red) conditions when wind speeds were reduced by 5 to $95 \%$ for the Llanberis and Clogwyn sites respectively. As expected, the impact of reduced wind speeds differed significantly between sites. At Llanberis (Fig. 9c), the relative proportion of different thermal conditions remained nearly constant, suggesting that there is little benefit obtained by reducing wind speed. This is unsurprising because conditions at Llanberis are naturally above critical limits (i.e. little black area was initially included). At Clogwyn (Fig. 9d), however, the probabilities of experiencing thermo-comfortable (green line) or thermo-neutral (blue line) conditions both increased significantly as the wind speed decreased. The probability of a thermally stressful condition (i.e. conditions requiring increased thermogenic compensation for heat loss) (red line) also increased but with a slighter gradient. Consequently, the probability of experiencing fatal (black line) conditions decreased greatly as wind speed decreased. Given a wind speed reduction of $60 \%$, for instance, we can reduce the chance of experiencing fatal thermal conditions by $27 \%$, whilst increasing the probability by $8 \%$ and $14 \%$ respectively of experiencing a thermo-comfortable (optimum for production) or thermo-neutral condition.
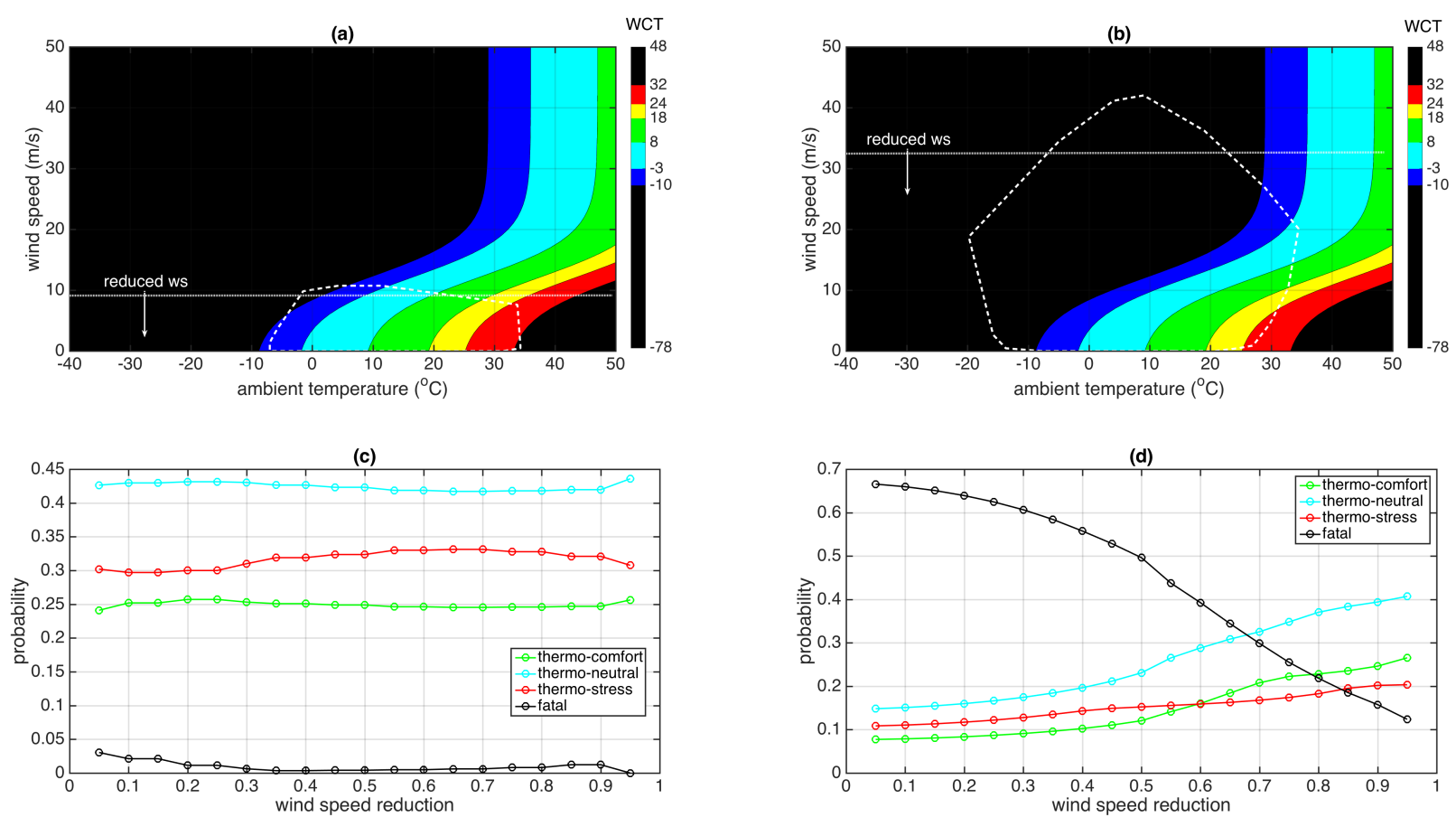
Modelling windbreak effects

condition against wind speed reduction. Line colour meaning: Green: thermo-comfort; Blue: thermo-neutral; Red: thermostress; Black: fatal.

\section{Discussions}

Eq. (1) was found to provide a good approximation to the two literature reports of wind speed reduction around windbreaks, and characterization was achieved using three model parameters with explicit relations to real-world parameters: downwind location of minimum wind speed $\left(x_{\min }\right.$, coefficient $\left.c\right)$, maximal percentage of wind speed reduction $\left(y_{\min }\right.$, coefficient $a$ ), and the distance over which $20 \%$ wind speed reduction is achieved $\left(L_{20}\right.$, see further discussion below), as given by Eqs. (2-4) respectively. Although coefficient $b$ was found to relate to $L_{20}$ through Eq. (4), the form of this equation was not clear enough to suggest an obvious physical meaning of $b$. In fact, the right-hand side of the formula also incorporates coefficients $a$ and $c$, making the interpretation of this parameter even more difficult. The hyperbolic function shown in Eq. (4), however, may suggest some deep relationship between the coefficient $b$ or $L_{20}$ with some fundamental aerodynamic process (e.g. an analytical solution of the Navier-Stokes equation under certain conditions). It is well known that the solutions to some equations that describe ocean waves can be represented by hyperbolic functions (Majda, 2003). Further analytical exploration of Eq. (4) and its links to fluid dynamics may be a fertile area to follow-up. This simple yet accurate three parameter characterization of wind reduction has been similarly achieved by other authors (Heisler and Dewalle, 1988; Wang and Takle, 1997; Yusaiyin and Tanaka, 2009), and the economy of the model will be pivotal in the generation of a computationally efficient tool for application to geospatial contexts in real-world farm planning.

In our ambition to develop a simple and transferrable model, we have endeavoured to correlate the parameters with a single driving variable. The concept of windbreak porosity has been frequently used in the literature as an intuitive structural feature to characterise a windbreak (Heisler and Dewalle, 1988; Torita and Satou, 2007; Wang and Takle, 1995; Zhou et al., 2005). However, empirical data is always required to determine the model parameters for any specific windbreak, and the differences depicted by the two literature datasets suggest that porosity alone is not able to unify these two datasets. Furthermore, as an index to describe how much wind resistance different windbreaks introduce, porosity or aerodynamic porosity has not, to our knowledge, been properly mathematically defined and is thus not a very useful term to apply computationally. Optical porosity may be well defined and can be calculated conveniently, however it may only be justifiable for 2-D windbreaks and may not 
work for 3-D situations (Torita and Satou, 2007; Zhou et al., 2005). Physically, porosity may represent a combination of several characteristics that reflect the complexity of a windbreak, such as tree and branch flexibility, leaf size, tortuosity, arrangements, etc. In aerodynamics,

444 drag force is often used to describe a windbreak (Guan et al., 2003; Wang and Takle, 1997), but similarly to porosity, this quantity is neither conveniently calculated nor measured. Future development of the model described herein will seek to determine a parsimonious and ecologically sound variable which may be used to more explicitly characterise the 3 dimensional structure of a windbreak.

449 The wind reduction data collected to parameterise our model apply to a deciduous windbreak in full foliage. It is important to note here, the considerable variability in shelter belt properties which are associated with species composition and seasonality of deciduous vegetation (Koh et al., 2014). These factors give further weight to the need for a unifying property that can be used to comprehensively define the 3D structure of windbreaks of varying phenology and species, and model potential wind speed reduction.

The effects of wind-chill on thermal tolerance limits of sheep, as demonstrated in Fig. 9, concur with observations elsewhere in the literature: Alexander (1974) observed the effect of wind upon critical temperature limits, noting that the critical temperature limits appeared to increase as wind speed increased. Whilst the animal's thermal tolerance does not alter (so long as insulation and physical properties remain constant), change in heat loss is proportional to both ambient temperature and wind speed (i.e. wind chill) (Mount and Brown, 1983 ) and thus with increasing wind speed, thermal limits are reached at effectively higher ambient temperatures. Calculations for convective heat loss in sheep reported in the literature vary according to means of measurement (deduced from oxygen consumption, radiative surface temperature, or power required to maintain internal heat of an electrical replica) and microclimatic factors affecting the experimental space (e.g. turbulence)(McArthur and Monteith, 1980a). However, the shape of the curve denoting each thermal boundary according to ambient temperature and wind speed presented in Fig. 9 reflects the step-wise breakdown of first boundary layer and then fleece structure, as observed by (Ames and Insley, 1975). It should be noted that the specific wind-chill model described here apply solely to the insulation and proportions of an adult medium-fleeced sheep. For example, the lower surface area: volume ratio and thinner fleece of a lamb would create more thermally stressful condition in a given thermal environment than experienced by an adult sheep, and thus the 
474 The wind-chill effect estimated in this study represented the heat loss from sheep through convection only, and a fuller description of the energetics of the endotherm body requires that consideration is also given to energy gained from the environment by radiation (most significantly direct solar) and the influence of precipitation (Brown and Mount, 1987; Clapperton et al., 1965; Matzarakis et al., 2010; McArthur, 1991). Here incoming and outgoing radiation should be considered in the model given the fact that windbreaks can normally provide shade from sunlight. This shading effect may be positive during hot conditions or negative when solar gain may exceed wind-chill in still, cold conditions. The data utilised to construct the wind-chill model presented in this paper were conducted in a laboratory with fixed radiative heating (Barnes, 1974), thus the validity of this model in assessing wind-chill effects remains. However, in addition to the spatial integration shown in this study, a temporal integration of positive heat flux (net benefit), over the full range of conditions experienced, should be made to obtain the total benefit over time. A companion paper focusing on the measurement and modelling of tree shading effects on animal heat loss is expected soon.

The WTT plot (Fig. 9) provides an intuitive visualisation for analysis of the wind-chill effects on the thermal stress or comfort experienced by a given organism in a given micro-climate. Generally, the climate conditions actually experienced at a particular location for a given time period are a sub area of the WTT plot. Results above indicate the greater gain in thermal stress reduction for livestock resulting from inclusion of shelter in the colder and windier

494 Clogwyn thermal condition compared to that at Llanberis. The information to be extracted 495 from this result is inspired: despite the benefits of windbreak practise in general, its effectiveness is dependent on micro-climate. Micro-climatic conditions which invoke a greater thermal stress as a result of being frequently beyond thermo-neutral and critical physiological limits (e.g. uplands) will gain greater benefit from incorporation of windbreaks.

499 For illustrative purposes here, we are comparing regions, however similar comparisons could

500 be made at farm scale to evaluate shelter options for different fields (of different elevation, aspect etc.) according to prevailing microclimate. Geospatial modelling of energetics, vegetation and meteorological has been used to predict range and survivorship of wild animals at landscape scale (Natori and Porter, 2007; Parker and Gillingham, 1990; Porter et al., 2002), and this model could form the basis of a similar approach, but with the aim of optimising the farmland landscape for production. Traditional hill farms in North Wales 
506

507

508

509

510

511

512

513

514

515

516

517

518

519

520

521

522

523

524

525

526

527

528

529

530

531

532

533

534

535

536

537

538

539

incorporate grazing sites from lowland to mountain top, so such a tool would be of great utility in cost: benefit assessments for investing in shelter provision across the farm landscape.

Further development of the WTT plot will provide more accurate quantification of the benefits of establishing a windbreak at a given location, by weighting each pair of wind speed and ambient temperature conditions by its frequency of occurrence rather than considered equally probable. Seasonal weather and extreme storm events are also likely to impact differently on animal thermal balance and welfare; thus, modelling of these meteorological scenarios separately may best inform effective shelter provision and weather-wise farm planning. Nevertheless, the thermal/wind envelope of a particular location, superimposed on the WTT plot for a given organism, provides a useful and convenient means of illustrating the response of livestock to wind-chill and to the effects introducing a windbreak and has been an effective tool for discussion of these subjects with non-experts (such as farmers). A follow-up study will focus on a spatial and temporal integration of the thermal benefits by combining the WTT plot and the windbreak model at a farm and landscape scale.

\section{Conclusions}

The models proposed in this paper, whilst simple, are effective in capturing real-world meteorological conditions and the resulting impacts of these on the thermal stress experienced by sheep. Wind chill has the potential to compromise farm productivity and animal welfare; windbreaks offer a mitigation of this by reducing local wind speed and resulting heat loss from livestock via convection. An organism-specific WTT plot may be used in a cost-benefit analysis of introducing windbreaks into real-world meteorological situations and may form the basis of an efficient and precise quantification of windbreak effects on animal productivity. The economy of the models described here offer significant potential for scaling up in computationally-efficient, spatially-explicit, applications for optimizing green infrastructure and scientifically-informed 'weather-wise' farm planning.

\section{Acknowledgements}

Yufeng He is supported by the joint $\mathrm{PhD}$ program between Bangor University - China Scholarship Council (CSC). Pippa Jones is supported through the Knowledge Economy Skills Scholarship (KESS) in partnership with the Woodland Trust. KESS is a pan-Wales higher level skills initiative led by Bangor University on behalf of the HE sector in Wales. It is part funded by the Welsh Government's European Social Fund (ESF) convergence programme for West Wales and the Valleys. The Author(s) acknowledge(s) the financial support provided by the Welsh Government and Higher Education Funding Council for Wales through the Sêr Cymru National Research Network for Low Carbon, Energy and 
540 Environment. We also thank First Hydro for providing the climate data at Llanberis and

541 Clogwyn stations.

542

543

544

545

546

547

548

549

550

551

552

553

554

555

556

557

558

559

560

561

562

563

564

565

566

567

568

569

570

571

572

573

574

575

576

577

578

579

580

581

582

583

584

585

\section{References}

Alexander, G., 1974. Heat loss from sheep, in: Monteith, J.L., Mount, L.E. (Eds.), Heat Loss from Animals and Man: Assessment and Control. Butterworths, London, pp. 173-203.

Alexander, G., Lynch, J.J., Mottershead, B.E., Donnelly, J.B., 1980. Reduction in lamb mortality by means of grass wind-breaks: results of a five-year study. Proc. Aust. Soc. Anim. Prod. 13, 329-332.

Ames, D.R., Insley, L.W., 1975. Wind-Chill effect for cattle and sheep. J. Anim. Sci. 40, 161165. doi:10.2134/jas1975.401161x

Barnes, T.A., 1974. Wind-chill index for sheep. Kansas State University.

Bianca, W., 1976. Significance of meteorology in animal production. Int. J. Biometeorol. 20, $139-156$.

Bianca, W., 1971. Die Anpassung des Haustieres an seine klimatische Umgebung. Schweiz. Landw. Forsch. 10, 155-205.

Bianca, W., 1968. Neuzeitliche Ergebnisse und Aufgaben der Bioklimatologie bei Haustieren. Der Tierzüchter 20, 438-442.

Bitog, J.P., Lee, I.B., Hwang, H.S., Shin, M.H., Hong, S.W., Seo, I.H., Kwon, K.S., Mostafa, E., Pang, Z., 2012. Numerical simulation study of a tree windbreak. Biosyst. Eng. 111, 4048. doi:10.1016/j.biosystemseng.2011.10.006

Blaxter, K.L., 1962. The energy metabolism of ruminants. Hutchinson, London.

Bligh, J., Ingram, D.L., Keynes, R.D., Robinson, S.G., 1965. The deep body temperature of an unrestrained Welsh Mountain sheep recorded by a radiotelemetric technique during a 12-month period. J. Physiol. 176, 136.

Brandle, J.R., Hodges, L., Zhou, X.H., 2004. Windbreaks in North American Agricultural Systems Windbreaks in North American Agricultural Systems. Agrofor. Syst. 61, 65-78.

Brown, D., Mount, L.E., 1987. Convective and radiative components of wind chill in sheep: estimation from meteorological records. Int. J. Biometeorol. 31, 127-140.

Clapperton, J.L., Joyce, J.P., Blaxter, K.L., 1965. Estimates of the contribution of solar radiation to the thermal exchanges of sheep at a latitude of 55 north. J. Agric. Sci. 64, 37-49.

Cleugh, H.A., 1998. Effect of windbreaks on air-flow, microclimate and productivity. Agroforesty Syst. 55-84.

Grace, J., 1988. Plant response to wind, Agriculture, Ecosystems \& Environment. Elsevier Science Publishers B.V. doi:10.1016/0167-8809(88)90008-4

Guan, D., Zhang, Y., Zhu, T., 2003. A wind-tunnel study of windbreak drag. Agric. For. Meteorol. 118, 75-84. doi:10.1016/S0168-1923(03)00069-8

CAgM Working Groups, 1989. Animal health and production at extremes of weather: reports of the CAgM Working Groups on Weather and Animal Disease and Weather and Animal Health. Secretariat of the World Meteorological Organization, Geneva, Switzerland.

Heisler, G.M., Dewalle, D.R., 1988. 2. Effects of windbreak structure on wind flow. Agric. Ecosyst. Environ. 22-23, 41-69. doi:10.1016/0167-8809(88)90007-2

Hipsey, M.R., 2003. Parameterizing the effect of a wind shelter on evaporation from small water bodies. Water Resour. Res. 39, 1-9. doi:10.1029/2002WR001784

Koh, I., Park, C.R., Kang, W., Lee, D., 2014. Seasonal effectiveness of a korean traditional 

deciduous windbreak in reducing wind speed. J. Ecol. Environ. 37, 91-97. doi:10.5141/ecoenv.2014.011

Majda, A., 2003. Introduction to PDEs and Waves for the Atmosphere and Ocean. American Mathematical Soc.

Matzarakis, A., Rutz, F., Mayer, H., 2010. Modelling radiation fluxes in simple and complex environments: basics of the RayMan model. Int. J. Biometeorol. 54, 131-139.

McArthur, A.J., 1991. Forestry and shelter for livestock. For. Ecol. Manage. 45, 93-107. doi:10.1016/0378-1127(91)90209-E

McArthur, A.J., Monteith, J.L., 1980a. Air movement and heat loss from sheep. I. Boundary layer insulation of a model sheep, with and without fleece. Proc. R. Soc. Lond. B. Biol. Sci. 209, 187-208.

McArthur, A.J., Monteith, J.L., 1980b. Air movement and heat loss from sheep. II. Thermal insulation of fleece in wind. Proc. R. Soc. London. Ser. B, Biol. Sci. 209, 209-17.

McDonald, A.G., Bealey, W.J., Fowler, D., Dragosits, U., Skiba, U., Smith, R.I., Donovan, R.G., Brett, H.E., Hewitt, C.N., Nemitz, E., 2007. Quantifying the effect of urban tree planting on concentrations and depositions of PM 10 in two UK conurbations. Atmos. Environ. $41,8455-8467$.

Mount, L.E., Brown, D., 1983. Wind chill in sheep: its estimation from meteorological records. Agric. Meteorol. 29, 259-268. doi:10.1016/0002-1571(83)90087-0

Mount, L.E., Brown, D., 1982. The use of meteorological records in estimating the effects of weather on sensible heat loss from sheep. Agric. Meteorol. 27, 241-255.

Natori, Y., Porter, W.P., 2007. Model of Japanese serow (Capricornis crispus) energetics predicts distribution on Honshu, Japan. Ecol. Appl. 17, 1441-1459. doi:10.1890/061785.1

Nord, M., 1991. Shelter effects of vegetation belts - Results of field measurements. Boundary-Layer Meteorol. 54, 363-385. doi:10.1007/BF00118867

Osczevski, R., Bluestein, M., 2005. The new wind chill equivalent temperature chart. Bull. Am. Meteorol. Soc. 86, 1453-1458. doi:10.1175/BAMS-86-10-1453

Parker, K.L., Gillingham, M.P., 1990. Estimates of Critical Thermal Environments for Mule Deer. J. Range Manag. 43, 73-81.

Pollard, J.C., 2006. Shelter for lambing sheep in New Zealand: a review. New Zeal. J. Agric. Res. 49, 395-404. doi:10.1080/00288233.2006.9513730

Porter, W.P., Sabo, J.L., Tracy, C.R., Reichman, O.J., Ramankutty, N., 2002. Physiology on a landscape scale: plant-animal interactions. Integr. Comp. Biol. 42, 431-453. doi:10.1093/icb/42.3.431

Schwartz, R.C., Fryrear, D.W., Harris, B.L., Bilbro, J.D., Juo, A.S.R., 1995. Mean flow and shear stress distributions as influenced by vegetative windbreak structure. Agric. For. Meteorol. 75, 1-22. doi:10.1016/0168-1923(94)02206-Y

Speckart, S.O., Pardyjak, E.R., 2014. Journal of Wind Engineering A method for rapidly computing windbreak $\mathrm{fl}$ ow fi eld variables 132, 101-108.

Středa, T., Středová, H., Rožnovský, J., 2011. Orchards Microclimatic Specifics, in: Bioclimate: Source and Limit of Social Development. pp. 132-133.

Stredova, H., Podhrazska, J., Litschmann, T., Streda, T., Roznovsky, J., 2012. Aerodynamic parameters of windbreak based on its optical porosity. Contrib. to Geophys. Geod. 3, 213-226. doi:10.2478/v10126-012-0008-5

Torita, H., Satou, H., 2007. Relationship between shelterbelt structure and mean wind reduction. Agric. For. Meteorol. 145, 186-194. doi:10.1016/j.agrformet.2007.04.018 
633

634

635

636

637

638

639

640

641

642

643

644

645

646

647

648

649

650

651

Vigiak, O., Sterk, G., Warren, A., Hagen, L.J., 2003. Spatial modeling of wind speed around windbreaks. Catena 52, 273-288. doi:10.1016/S0341-8162(03)00018-3

Wang, H., Takle, E.S., 1997. Momentum budget and shelter mechanism of boundary-layer flow near a shelterbelt. Bound. Layer Meteorol. 82, 417-435. doi:10.1023/A:1000262020253

Wang, H., Takle, E.S., 1995. Boundary-layer flow and turbulence near porous obstacles. Boundary-Layer Meteorol. 74, 73-88. doi:10.1007/BF00715711

Yusaiyin, M., Tanaka, N., 2009. Effects of windbreak width in wind direction on wind velocity reduction. J. For. Res. 20, 199-204. doi:10.1007/s11676-009-0039-6

Zhang, H., Brandle, J.R., Meyer, G.E., Hodges, L., 1995. A model to evaluate windbreak protection efficiency. Agrofor. Syst. 29, 191-200. doi:10.1007/BF00704868

Zhou, X.H., Brandle, J.R., Mize, C.W., Takle, E.S., 2005. Three-dimensional aerodynamic structure of a tree shelterbelt: Definition, characterization and working models. Agrofor. Syst. 63, 133-147. doi:10.1007/s10457-004-3147-5

Zhou, X.H., Brandle, J.R., Takle, E.S., Mize, C.W., 2007. Relationship of three-dimensional structure to shelterbelt function: A theoretical hypothesis, in: Batish, D.R., Kohli, R.K., Jose, S., Singh, H.P. (Eds.), Ecological Basis of Agroforestry. Taylor \& Francis, Boca Raton, FL, pp. 273-285. doi:10.1201/9781420043365.pt3 